\title{
Control Allocation of a GEO Satellite for Station-Keeping and Momentum Management by Using Thrusters and Reaction Wheels
}

\author{
Kezban Üçüncü Emri ${ }^{1 *}$, Onur Cihan ${ }^{2}$ \\ 1* Marmara University, Faculty of Engineering, Department of Electrical and Electronics Engineering, İstanbul, Turkey \\ TÜBİTAK Space Technologies Research Institute, Ankara, Turkey, (ORCID: 0000-0002-7496-9274), kezban.ucuncu@tubitak.gov.tr \\ 2 Marmara University, Faculty of Engineering, Department of Electrical and Electronics Engineering, İstanbul, Turkey, (ORCID: 0000-0002-5729-2417), \\ onur.cihan@marmara.edu.tr
}

(3rd International Congress on Human-Computer Interaction, Optimization and Robotic Applications June 11-13, 2021)

(DOI: $10.31590 /$ ejosat.958404)

ATIF/REFERENCE: Üçüncü Emri, K., Cihan, O. (2021). Control Allocation of a GEO Satellite for Station-Keeping and Momentum Management by Using Thrusters and Reaction Wheels. European Journal of Science and Technology, (26), 374-382.

\begin{abstract}
This paper presents a control allocation method for simultaneous station-keeping and momentum management maneuvers. The considered satellite model is equipped with internal and external actuators to control the satellite's orbit and attitude and, concurrently, unload the angular momentum stored in the reaction wheels. Our method allocates the external and internal actuators to achieve the control objectives. Internal actuators such as reaction wheels generate torque based on the conservation of the momentum. In this study, two different controllers are utilized to control satellite attitude and reaction wheel speeds. To manage the satellite attitude in three axes, at least three reaction wheels are needed. In this study, four reaction wheels are used to ensure control in case of failure of a reaction wheel. In addition, with six chemical thrusters, east-west and north-south orbit correction maneuvers are performed. For the satellite to serve throughout its service life, fuel optimization of the satellite is required. The proposed control allocation method will enforce constraints that maintain orbital accuracy and the satellite in a nadir pointing attitude configuration while minimizing the use of thrusters, significantly reducing fuel consumption. The method combines the two generally separated objectives of orbital and attitude control through constraints determined by the propulsion system. Numerical simulations are performed to validate the proposed method. The simulations show that using the proposed control allocation method can significantly increase the service life of geostationary satellites.
\end{abstract}

Keywords: Momentum Management, Station Keeping, Optimization, Control Allocation, Reaction Wheel, Geostationary Satellite.

\section{İtici ve Tepki Tekeri Kullanarak Yerdurağan Uyduların Yönelim Sağlama ve Yörünge Düzeltmesi için Bir Kontrol Dağıtımı Yöntemi Geliştirilmesi}

$\ddot{O} \mathbf{z}$

Bu çalışmada yerdurağan yörüngedeki bir uydunun eşzamanlı olarak yörünge düzeltmesi ve momentum yönetimi yapabilmesi için bir kontrol dağıtım yöntemi önerilmektedir. Ele alınan uydu modeli, uydunun yönelimini ve yörüngesini kontrol etmesi ve aynı zamanda tepki tekerlerinde depolanan açısal momentumu boşaltmak için koordine edilmesi gereken içsel ve dişsal eyleyiciler ile donatılmıştır. Yöntem, kontrol hedeflerine ulaşmak için içsel ve dışsal eyleyicilerin birleşiminin nasıl dağıtıldığını gösterir. Tepki/momentum tekerleri gibi iç eyleyiciler momentumun korunmasına dayalı tork üretirler. Bu çalışmada uydu yönelimini ve tepki tekeri hızlarını

* Corresponding Author: kezban.ucuncu@tubitak.gov.tr 
kontrol eden iki farklı kontrolcü tasarlanmıştır. Uydu yöneliminin üç eksende kontrol edilebilmesi için en az 3 adet tepki tekerine ihtiyaç vardır. Bu çalışmada herhangi bir tekerin arızalanması durumunda kontrolün sağlanabilmesi için dört adet tepki tekeri kullanılmıştır. Buna ek olarak, kullanılan altı adet kimyasal itici ile Doğu-Batı ve Kuzey-Güney yörünge düzeltme manevraları yapılabilmektedir. Uydunun görev ömrü boyunca hizmet verebilmesi için uydudaki yakıt kullanımının optimize edilmesi gerekir. Önerilen kontrol dağıtım yöntemi, iticilerin kullanımını en aza indirerek yakıt tüketimini önemli ölçüde azaltırken, yörünge doğruluğu ve ayakucu noktasını işaret eden bir yönelim yapılandırmasında uyduyu koruyan kısıtlamaları uygulamaktadır. Yöntem, yörünge ve yönelim kontrolünün genellikle ayrıştırılmış iki hedefini tahrik sistemi üzerindeki belirlenen kısıtlamalar yoluyla birleştirir. Önerilen yöntemi doğrulamak için sayısal simülasyonlar gerçekleştirilmiştir. Yapılan simülasyonlar, önerilen kontrol dağıtım yönteminin kullanılmasının yerdurağan uyduların hizmet ömrünü önemli ölçüde arttırabileceğini göstermektedir.

Anahtar Kelimeler: Momentum Boşaltma, Mevzi Koruma, Kimyasal İtki Sistemi, Tepki Tekeri, Eniyileme, Yerdurağan Uydu.

\section{Introduction}

Satellites in Geosynchronous Earth Orbit (GEO) are referred to as geostationary satellites since they seem fixed as they move at the same angular velocity as the Earth and orbit along a path parallel to Earth's rotation. They provide coverage to a specific area. GEO satellites are subjected to various nonKeplerian forces and disturbance torques constantly, resulting in a deviation from the satellite's desired orbital position (BongKyu Park et al., 2005). For satellites in GEO, the main perturbations are solar and lunar gravitational attractions that induce drift in orbital inclination, solar radiation pressure that affects orbit eccentricity (Losa, 2007). Therefore, in order to counter the disturbance forces and torques while maintaining satellite attitude, station-keeping is required. Station-keeping includes a series of orbit correction maneuvers implemented by the thrusters (Weiss, Kalabic, \& Cairano, 2018; Satpute, \& Emami, 2019).

Although the electric propulsion system appears to be a viable alternative due to the critical reduction in satellite mass, they produce relatively low thrust compared to chemical propulsion. It can achieve much higher specific impulses than chemical propulsion. Chemical thrusters generate higher thrust with lower specific impulses. Therefore, they can rarely fire for short periods when implementing the station-keeping maneuvers. A short thrust period is sufficient for the $\Delta \mathrm{V}$ required to perform these maneuvers. Electric thrusters, however, provide low thrust at high specific impulses. Thus, they must fire for long periods to manage the same $\Delta \mathrm{V}$ as chemical thrusters (Thomas, 2016). Consequently, an electric propulsion system is not preferred for conventional station-keeping strategies. Presently, most GEO satellites are equipped with chemical thrusters.

In the literature, there are many examples of station-keeping techniques. Chao and Baker (1983) discussed orbit propagation and station-keeping of GEO satellites. Guelman (2014) proposed a real-time closed-loop orbit control for station-keeping of the GEO satellites with electric thrusters, perturbations are excluded, and optimization of the thrusters' usage is not considered. Shrivastava (1978) discussed station-keeping methods and perturbation environments in GEO satellites. Furthermore, Frederik J. de Bruijn (2016) presented a method that can be used for station-keeping with a convex optimization technique. The method is generic and can be applied to both chemical and electrical propulsion systems. It is aimed to minimize fuel consumption with thruster optimization. Emma and Pernicka (2003) proposed a three-phase algorithm that couples longitude control with eccentricity control autonomously. Losa (2007) focused on comparing station-keeping maneuver planning methods for geostationary satellites equipped with electrical and chemical thrusters. However, momentum management of the satellite was not considered in these work. There is no attitude control for nadir pointing satellite. Simultaneous station-keeping and momentum management of GEO satellites with electrical thrust is discussed in (Weiss, Kalabic, \& Cairano, 2018; Satpute, \& Emami, 2019).

GEO satellites perturb from environmental torques that disturb the satellite attitude. Reaction wheels can be used to counteract the effects of disturbing torques. Therefore, momentum management is required periodically to overcome these disturbing torques. In order to maintain the satellite attitude, the disturbing torques must be absorbed by the reaction wheels. Reaction wheels cannot rotate at randomly high speeds. The reaction wheels begin to saturate after a while and the momentum stored by the reaction wheels must be unloaded. The momentum accumulated in the reaction wheels should be unloaded using the thrusters. The usage of thrusters needs to be optimized to minimize fuel consumption of satellite.

In this paper, we use convex quadratic and population-based optimization algorithms for station-keeping and momentum management of GEO satellites equipped with chemical thrusters and reaction wheels. Population-based optimization algorithm ensures the attitude controller performance and the convex optimization method is used for thruster optimization. To generate the concurrent reaction wheel momentum control and station-keeping maneuver, orbital and attitude dynamics are considered simultaneously. The satellite with realistic thruster and reaction wheel configurations are discussed for the applicability of the proposed method. To the best of the authors' knowledge, no study focuses on station-keeping and momentum unloading maneuvers with chemical thrusters concurrently.

The main contributions of this method proposed in this paper can be summarized as follows:

1. Keeping the satellite in a nadir-pointing configuration at all times,

2. Maintaining the satellite in a station-keeping box,

3. Not exceeding the saturation limits of angular velocity of the reaction wheels,

4. Unloading the stored angular momentum from the reaction wheels,

5. Minimizing the fuel consumption with proposed optimization algorithm.

The rest of the paper is organized as follows. In Section 2, kinematic and dynamic models of the satellite as well as the attitude and wheel speed controller models are given. Furthremore, the optimization problems are proposed for the attitude controller and thruster allocation. The numerical results 
that highlight the proposed method are presented in Section 3. Finally, we conclude the paper in Section 4.

\section{Material and Method}

In this section we give the kinematic and dynamical models of the satellite and formulate the optimization problem.

\subsection{Kinematic and Dynamic Models}

This section consists of the concepts of the orbital dynamics, attitude kinematics and attitude dynamics of GEO satellites.

\subsubsection{Notation Preliminaries}

In this paper, we denote an arbitrary reference frame $a$ with $\mathcal{F}_{a}$. By $\bar{w}_{a / b}{ }^{(c)}$, we define the angular velocity of $\mathcal{F}_{a}$ with respect to $\mathcal{F}_{b}$, expressed in $\mathcal{F}_{c} . \bar{x}^{(a)}$ denotes the column matrix representation of $\vec{x}$ expressed in $\mathcal{F}_{a}$ (for further information, see (Özgören, 2007)).

Figure 1. Functional architecture of the system

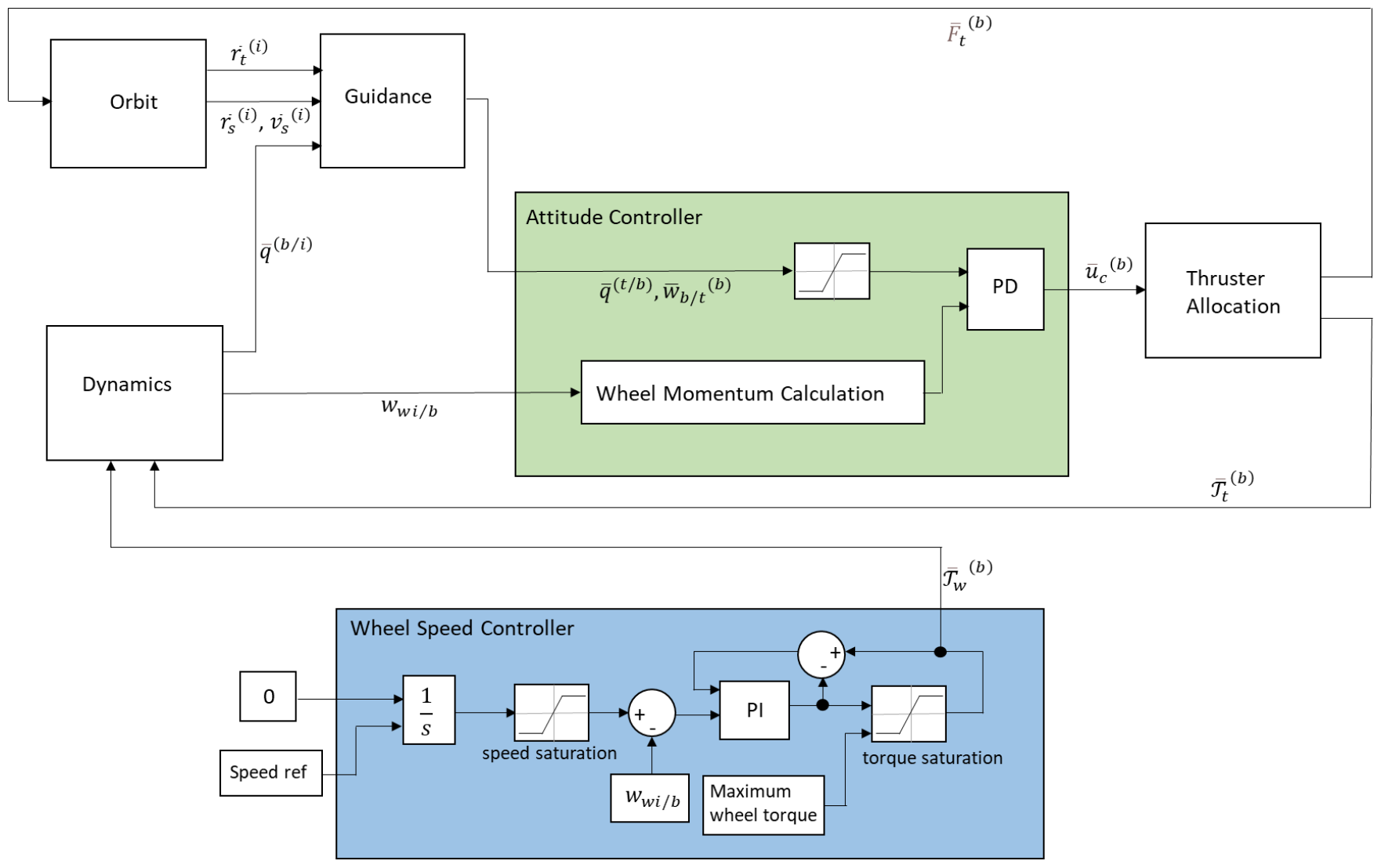

Table 1. Nomenclature

\begin{tabular}{clc}
\hline Parameter & \multicolumn{1}{c}{ Definition } & Unit \\
\hline$\vec{a}_{\text {moon }}$ & lunar perturbation acceleration vector & $\mathrm{km} / \mathrm{s}^{2}$ \\
\hline$\vec{a}_{\text {sun }}$ & solar perturbation acceleration vector & $\mathrm{km} / \mathrm{s}^{2}$ \\
\hline$\vec{a}_{p}$ & total perturbation acceleration vector & $\mathrm{km} / \mathrm{s}^{2}$ \\
\hline$A_{u}$ & allocation matrix & - \\
\hline$b$ & SCA constant & $\mathrm{N}$ \\
\hline$\hat{C}^{(b, t)}$ & rotation matrix that transforms coordinates from $\mathcal{F}_{t}$ to $\mathcal{F}_{b}$ & $\mathrm{~N}$ \\
\hline$F$ & force generated in the maneuver direction $\left(F_{x}\right.$ or $\left.F_{y}\right)$ & $\mathrm{N}$ \\
\hline$F_{\text {max }}$ & maximum allowable thrust & $\mathrm{kgm} / \mathrm{s}$ \\
\hline $\bar{F}_{t}^{(b)}$ & thruster forces expressed in $\mathcal{F}_{b}$ & $\mathrm{~kg} / \mathrm{m}^{2}$ \\
\hline $\bar{H}_{w}{ }^{(b)}$ & angular momentum of the reaction wheels along their spin axes & $\mathrm{kg} / \mathrm{m}^{2}$ \\
\hline$\hat{J}_{s}^{(b)}$ & satellite moment of inertia & \\
\hline$J_{w i}$ & i-th reaction wheel moment of inertia & \\
\hline
\end{tabular}




\begin{tabular}{|c|c|c|}
\hline$k$ & current iteration & - \\
\hline$K$ & maximum number of iterations & - \\
\hline$K_{d}$ & attitude controller derivative gain & - \\
\hline$K_{i, w}$ & wheel speed controller integral gain & - \\
\hline$K_{p}$ & attitude controller proportional gain & - \\
\hline$K_{p, w}$ & wheel speed controller proportional gain & - \\
\hline$K_{t, w}$ & wheel speed controller anti-windup gain & - \\
\hline$m$ & satellite mass & $\mathrm{kg}$ \\
\hline$\mu$ & Earth's gravitational constant & $\mathrm{km}^{3} / \mathrm{s}^{2}$ \\
\hline$\mu_{\text {moon }}$ & lunar gravitational constant & $\mathrm{km}^{3} / \mathrm{s}^{2}$ \\
\hline$\mu_{\text {sun }}$ & solar gravitational constant & $\mathrm{km}^{3} / \mathrm{s}^{2}$ \\
\hline$n_{\text {wheel }}$ & number of the reaction wheel & - \\
\hline$w_{w i / b}$ & angular velocity of the $i$-th reaction wheel in spin axes with respect to $\mathcal{F}_{b}$ & $\mathrm{rad} / \mathrm{s}$ \\
\hline$\widetilde{w}_{b / i}^{(b)}$ & cross product matrix of $\bar{w}_{b / i}{ }^{(b)}$ & - \\
\hline$\Omega$ & skew symmetric matrix & - \\
\hline $\bar{q}$ & attitude quaternion & - \\
\hline $\bar{q}_{\text {err }}(b / i)$ & saturated quaternion error of $\mathcal{F}_{b}$ with respect to $\mathcal{F}_{i}$ & - \\
\hline$P_{i}^{t}$ & position of the destination point in $i$-th dimension at $t$-th iteration & \\
\hline $\bar{r}^{(i)}$ & satellite position vector in $\mathcal{F}_{i}$ & $\mathrm{~km}$ \\
\hline$r_{1}, r_{2}, r_{3}, r_{4}$ & random numbers & - \\
\hline $\bar{r}_{\text {moon }}{ }^{(i)}$ & position of the moon & $\mathrm{km}$ \\
\hline $\bar{r}_{\text {sun }}(i)$ & position of the sun & $\mathrm{km}$ \\
\hline $\bar{r}_{t i}^{(b)}$ & position of the $i$-th thruster in $\mathcal{F}_{b}$ & $m$ \\
\hline$\overline{\mathcal{T}}_{t}^{(b)}$ & torques provided by the thrusters in $\mathcal{F}_{b}$ & $N m$ \\
\hline$\overline{\mathcal{T}}_{w}^{(b)}$ & reaction wheel torques in $\mathcal{F}_{b}$ & $N m$ \\
\hline$u$ & desired thrust vector & \\
\hline $\bar{u}_{c}^{(b)}$ & control torque in $\mathcal{F}_{b}$ & $\mathrm{Nm}$ \\
\hline $\bar{u}_{w i}{ }^{(b)}$ & unit vector of the $i$-th reaction wheel in $\mathcal{F}_{b}$ & - \\
\hline $\bar{u}_{t i}{ }^{(b)}$ & unit vector of the $i$-th thruster in $\mathcal{F}_{b}$ & - \\
\hline $\bar{v}^{(i)}$ & satellite velocity vector in $\mathcal{F}_{i}$ & $\mathrm{~km} / \mathrm{s}$ \\
\hline$X_{i}^{t}$ & position of the current solution in $i$-th dimension at $t$-th iteration & - \\
\hline
\end{tabular}

\subsubsection{Functional Architecture}

In this study, system design is composed of six sections. Figure 1 illustrates the functional architecture of the system whose details are given in the following sections.

Orbit block calculates the current satellite position and velocity, whereas Dynamics block contains the dynamical equations related with the motion of the satellite and generates reaction wheel speed, angular velocity, and attitude of the satellite. Guidance block computes the attitude and angular velocity in the desired reference frame which are the inputs of the Attitude Controller block. Attitude Controller block calculates the desired torque by not exceeding the maximum tolerable attitude error. Thruster Allocation block solves the optimum thruster usage problem. Finally, the Wheel Speed Controller block controls the reaction wheel speed for momentum unloading of the reaction wheels.

\subsubsection{Orbital Dynamics}

This section describes the design and implementation of the orbit model which will be further utilized to define satellite motion. The nonlinear equation of motion of the satellite is given by

$$
\ddot{\bar{r}}(i)=-\mu \frac{\bar{r}^{(i)}}{r^{3}}+\frac{1}{m} \bar{F}_{t}^{(b)}+\vec{a}_{p}
$$

where $\mu$ is the Earth's gravitational constant, $m$ is the mass of the satellite, $\bar{F}_{t}^{(b)}$ is the external forces applied to the satellite by the thrusters, $\bar{r}^{(i)}$ is the satellite position vector in inertial frame (ECI, $\mathcal{F}_{i}$ ) and $\vec{a}_{p}$ is the total perturbation acceleration. Common perturbations are non-spherical central body, solar radiation pressure, and moon and sun gravitational interactions (Curtis, 2010). For GEO satellites, the main perturbations are the lunar and solar gravitational attractions, which include a drift in orbital inclination (Losa, 2007). These perturbation accelerations are formulated as

$$
\begin{gathered}
\vec{a}_{\text {moon }}=\mu_{\text {moon }}\left(\frac{\bar{r}_{\text {moon }}{ }^{(i)}-\bar{r}^{(i)}}{\left|\bar{r}_{\text {moon }}{ }^{(i)}-\bar{r}^{(i)}\right|^{3}}-\frac{\bar{r}_{\text {moon }}{ }^{(i)}}{\left|\bar{r}_{\text {moon }}{ }^{(i)}\right|^{3}}\right) \\
\vec{a}_{\text {sun }}=\mu_{\text {sun }}\left(\frac{\bar{r}_{\text {sun }}{ }^{(i)}-\bar{r}^{(i)}}{\left|\bar{r}_{\text {sun }}{ }^{(i)}-\bar{r}^{(i)}\right|^{3}}-\frac{\bar{r}_{\text {sun }}{ }^{(i)}}{\left|\bar{r}_{\text {sun }}{ }^{(i)}\right|^{3}}\right) \\
\vec{a}_{p}=\vec{a}_{\text {moon }}+\vec{a}_{\text {sun }}
\end{gathered}
$$


where $\mu_{\text {moon }}$ and $\mu_{\text {sun }}$ are the lunar and solar gravitational constants, respectively. Also, $\bar{r}_{\text {moon }}{ }^{(i)}$ and $\bar{r}_{\text {sun }}{ }^{(i)}$ are the positions of the moon and sun, respectively.

\subsubsection{Attitude Kinematics}

In this section, the kinematics of the attitude are discussed. We represent the attitude of the satellite by a quaternion, which leads to the following representation for the attitude kinematics (Markley, \& Crassidis, 2014)

$$
\dot{\bar{q}}^{(b / i)}(t)=\frac{1}{2} \Omega\left(\bar{w}_{b / i}^{(b)}(t)\right) \bar{q}^{(b / i)}(t)
$$

where $\bar{q}=\left[q_{1} q_{2} q_{3} q_{4}\right]^{T}$ is the quaternion vector formed of four attitude parameters and $\Omega\left(\bar{w}_{b / i}{ }^{(b)}\right)$ is the skew symmetric matrix which can be expressed as

$$
\Omega\left(\bar{w}_{b / i}{ }^{(b)}\right)=\left[\begin{array}{cccc}
0 & w_{z} & -w_{y} & w_{x} \\
-w_{z} & 0 & w_{x} & w_{y} \\
w_{y} & -w_{x} & 0 & w_{z} \\
-w_{x} & -w_{y} & -w_{z} & 0
\end{array}\right] .
$$

The angular velocity vector in $\mathcal{F}_{b}$ with respect to inertial frame $\mathcal{F}_{i}$, expressed in $\mathcal{F}_{b}$ is stated separately as $\bar{w}_{b / i}{ }^{(b)}=$ $\left[\begin{array}{lll}w_{x} & w_{y} & w_{z}\end{array}\right]^{T}$. The attitude kinematics can be expressed by an attitude matrix, quaternion products and the angular velocity vector. See for further information (Markley, \& Crassidis, 2014).

\subsubsection{Attitude Dynamics with Reaction Wheels}

The satellite rigid body attitude dynamics are actuated by the reaction wheels. The equation of motion for the attitude dynamics of the satellite can be expressed in body fixed frame $\mathcal{F}_{b}$ as

$$
\begin{aligned}
& \dot{\bar{W}}_{b / i}{ }^{(b)}=\hat{J}_{s}{ }^{(b)}{ }^{-1}\left[\overline{\mathcal{T}}^{(b)}-\overline{\mathcal{T}}_{w}{ }^{(b)}-\widetilde{w}_{b / i}{ }^{(b)}\left(\hat{U}_{s}{ }^{(b)} \bar{w}_{b / i}{ }^{(b)}\right.\right. \\
& \left.\left.+\sum_{i=1}^{n_{w h e e l}} J_{w i} w_{w i / b} \bar{u}_{w i}{ }^{(b)}\right)\right]
\end{aligned}
$$

where $\dot{\bar{W}}_{b / i}{ }^{(b)}$ is the derivative of the angular velocity vector in $\mathcal{F}_{b}$ with respect to $\mathcal{F}_{i}$, expressed in $\mathcal{F}_{b} ; \hat{J}_{s}{ }^{(b)}$ and $J_{w i}$ are the satellite inertia and $i$-th reaction wheel inertia, respectively. $\overrightarrow{\mathcal{T}}_{t}^{(b)}$ and $\overrightarrow{\mathcal{T}}_{w}{ }^{(b)}$ are the torques provided by thrusters and reaction wheels' torque vectors, respectively. $w_{w i / b}$ is the angular velocity of the $i$-th reaction wheel in spin axes, $n_{\text {wheel }}=$ 4 is the number of the reaction wheels and $\bar{u}_{w i}{ }^{(b)}$ is the unit vector of the $i$-th reaction wheel. Unit vectors of the reaction wheels are as follows

$$
\begin{aligned}
& \bar{u}_{w 1}{ }^{(b)}=\frac{1}{\sqrt{3}}\left[\begin{array}{l}
1 \\
1 \\
1
\end{array}\right], \bar{u}_{w 2}{ }^{(b)}=\frac{1}{\sqrt{3}}\left[\begin{array}{r}
1 \\
1 \\
-1
\end{array}\right], \\
& \bar{u}_{w 3}{ }^{(b)}=\frac{1}{\sqrt{3}}\left[\begin{array}{r}
-1 \\
1 \\
-1
\end{array}\right], \bar{u}_{w 4}{ }^{(b)}=\frac{1}{\sqrt{3}}\left[\begin{array}{r}
-1 \\
1 \\
1
\end{array}\right]
\end{aligned}
$$

A minimum of three reaction wheels are required for control in three axes. In the system under consideration, four reaction e-ISSN: 2148-2683 wheels are used. It is assumed that these reaction wheels are placed in a square pyramidal structure so that they can generate torque in all directions. Figure 2 illustrates configuration of the reaction wheels. Thanks to this arrangement, the amount of torque on the reaction wheels in any maneuver can be kept on an equal level. The surface normal of the square based pyramid are the momentum axes of the reaction wheels.

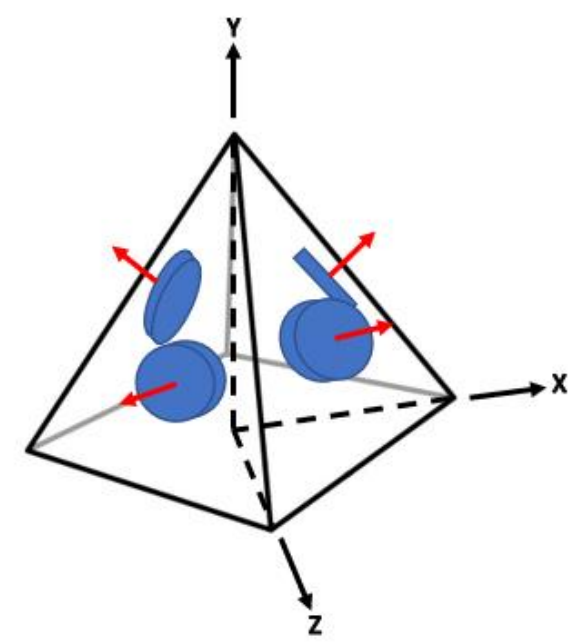

Figure 2. Square based pyramid structure used in reaction wheel configuration

The satellite consists of six thrusters as depicted in Figure 3. Thrusters are distributed over the satellite's north, east and west panels which allows the torque to be applied in any direction and the force to be applied in $+x,-x$ and $-y$ directions. Thus, orbit correction is planned regarding available force directions.

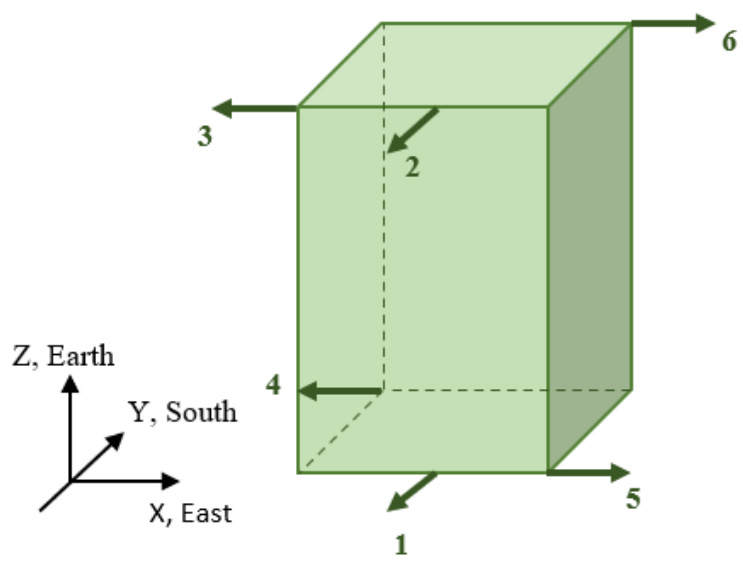

Figure 3. Placement of the thrusters

\subsubsection{Guidance Algorithm}

In GEO, satellite will be controlled according to the target frame $\mathcal{F}_{t}$ which is referenced to the satellite's orbit. Note that $z$ axis of the target frame is pointing the target point. The $x$ axis is aligned with the velocity vector. The cross product of the $x$ and $z$ axes is the $y$ axis which is opposite to the orbital plane normal. The $x$ axis is normal to the position vector and positive in the direction of the velocity vector. 


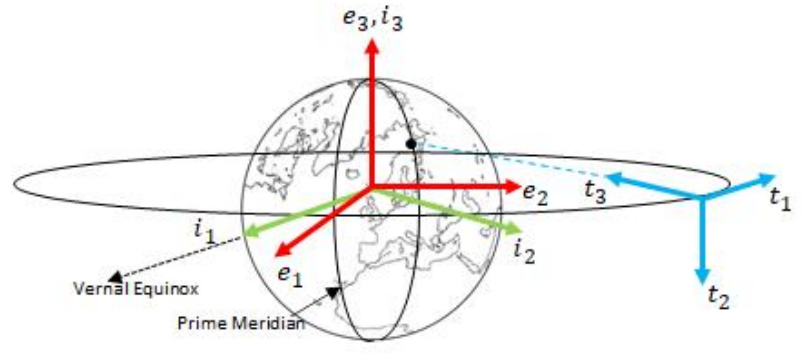

Figure 4. Target, ECI and ECEF frame used for guidance model

The Guidance algorithm calculates $\bar{q}^{(t / i)}, \bar{q}^{(t / b)}, \bar{w}_{b / t}{ }^{(b)}, \bar{w}_{t / i}{ }^{(t)}$. Using the satellite position $\vec{r}^{(i)}$ and velocity $\vec{v}^{(i)}$ vectors that are calculated in the Orbit model in $\mathcal{F}_{i}$, $\bar{q}^{(t / i)}$ is extracted from the attitude matrix. $\bar{q}^{(b / i)}$ is calculated by using the attitude kinematics. $\bar{q}^{(t / b)}$ is quaternion error between $\bar{q}^{(b / i)}$ and $\bar{q}^{(t / i)}$. The relationship between $\bar{w}_{b / t}{ }^{(b)}$ and $\bar{w}_{b / i}{ }^{(b)}$ is given as

$$
\bar{w}_{b / t}{ }^{(b)}=\bar{w}_{b / i}{ }^{(b)}-\hat{C}^{(b, t)} \bar{w}_{t / i}{ }^{(t)} .
$$

where $\bar{w}_{b / t}{ }^{(b)}$ indicates the angular velocity in body frame $\mathcal{F}_{b}$ with respect to target frame $\mathcal{F}_{t}$, expressed in $\mathcal{F}_{b}$ where $\bar{w}_{b / i}{ }^{(b)}$ is obtained from attitude dynamics equations, $\bar{w}_{t / i}{ }^{(t)}$ is function of $\dot{\bar{q}}^{(t / i)}$, and $\hat{C}^{(b, t)}$ is the rotation matrix that transforms coordinates from $\mathcal{F}_{t}$ to $\mathcal{F}_{b} . \widetilde{w}_{b / i}{ }^{(b)}$ is the cross product matrix of $\bar{w}_{b / i}{ }^{(b)}$ that can be computed as

$$
\widetilde{w}_{b / i}{ }^{(b)}=\left[\begin{array}{ccc}
0 & -w_{z} & w_{y} \\
w_{z} & 0 & -w_{x} \\
-w_{y} & w_{x} & 0
\end{array}\right] .
$$

\subsubsection{Controller Design}

The task of the control function is to set the attitude of the satellite to a desired value determined according to the reference frame. Attitude Controller calculates the desired amount of torque from the actuator using the desired attitude and angular velocity parameters. For attitude control, we propose a PD type controller where the parameters $K_{p}$ and $K_{d}$ are chosen with Sine Cosine Algorithm (SCA) (Mirjalili, 2016).
In attitude control problem, the objective is to minimize the integral of the saturated quaternion error while keeping the controller parameters in a practical range. The optimization problem can be formulated as follows

$$
\begin{gathered}
\text { minimize } \int_{0}^{100}\left(\bar{q}_{\text {err }}{ }^{(b / i)}\right)^{2} d t \\
\text { subject to } K_{p}, K_{d} \leq 50000 K_{p}, K_{d} \geq 1
\end{gathered}
$$

where $\bar{q}_{e r r}{ }^{(b / i)}$ is saturated quaternion error.

The internal and external torques applied to the satellite must be controlled in order to control attitude and keep the angular velocity of the satellite at the desired value. Angular momentum of the reaction wheels along their spin axes can be written as

$$
\bar{H}_{w}{ }^{(b)}=\sum_{i=1}^{n_{w h e e l}} J_{w i} w_{w i / b} \bar{u}_{w i}{ }^{(b)} .
$$

Due to the non-periodic and accumulated disturbing torques, the reaction wheels reach their momentum limit values and cannot generate more torque. Because of this, satellite cannot ensure the attitude. Therefore, the momentum unloading of the reaction wheels is needed in order to counteract this disturbance torques. The thrusters are given the torque command to reduce the speed of the reaction wheels. Control torque distributed to the thrusters is calculated as

$$
\begin{aligned}
& \bar{u}_{c}^{(b)}= \\
& \left.K_{p} \bar{q}_{e r r}{ }^{(b / i)}-K_{d} \bar{w}_{b / t}{ }^{(b)}-\widetilde{w}_{b / i}{ }^{(b)} \hat{J}_{s}^{\left({ }^{b}\right)} \bar{w}_{b / i}{ }^{(b)}+\bar{H}_{w}{ }^{(b)}\right) .
\end{aligned}
$$

Obtained torque is distributed to six thrusters in the Thruster Allocation block shown in Figure 1.

The block shown at the bottom of the Figure 1 illustrates the reaction wheel control mechanism. We use a PI type controller to bring the wheels to desired speed. Note here that anti-windup part prevents integration wind-up in PI controller to eliminate the windup problem of the controller.

Table 2. Unit vector of the thruster

\begin{tabular}{|c|c|c|c|c|c|}
\hline Thruster & Unit vector & Thruster & Unit vector & Thruster & Unit vector \\
\hline 1 & $\bar{u}_{t 1}{ }^{(b)}=\left[\begin{array}{l}0 \\
1 \\
0\end{array}\right]$ & 3 & $\bar{u}_{t 3}{ }^{(b)}=\left[\begin{array}{l}1 \\
0 \\
0\end{array}\right]$ & 5 & $\bar{u}_{t 5}{ }^{(b)}=\left[\begin{array}{r}-1 \\
0 \\
0\end{array}\right]$ \\
\hline 2 & $\bar{u}_{t 2}{ }^{(b)}=\left[\begin{array}{l}0 \\
1 \\
0\end{array}\right]$ & 4 & $\bar{u}_{t 4}{ }^{(b)}=\left[\begin{array}{l}1 \\
0 \\
0\end{array}\right]$ & 6 & $\bar{u}_{t 6}{ }^{(b)}=\left[\begin{array}{r}-1 \\
0 \\
0\end{array}\right]$ \\
\hline
\end{tabular}




\subsection{Optimization Problem}

\subsubsection{SCA Algorithm}

Sine-Cosine Algorithm (SCA) is a population-based heuristic optimization technique proposed by Mirjalili (2016) to solve optimization problems. SCA is based on sine cosine mathematical functions and uses these functions to explore and exploit space between two solutions in the search space to find the best solution.

SCA initially generates multiple random solutions. Also, it provides the best solution or moving them away. In addition, several random and adaptive variables are integrated into the algorithm to strengthen the exploration and exploitation are two extensive stages of the stochastic population-based optimization process, and the position update equations for SCA include these stages as below

$$
X_{i}{ }^{t+1}=\left\{\begin{array}{l}
X_{i}{ }^{t}+r_{1} \times \sin \left(r_{2}\right) \times\left|r_{3} P_{i}{ }^{t}-X_{i}{ }^{t}\right|, r_{4}<0.5 \\
X_{i}{ }^{t}+r_{1} \times \cos \left(r_{2}\right) \times\left|r_{3} P_{i}{ }^{t}-X_{i i}{ }^{t}\right|, r_{4} \geq 0.5
\end{array}\right.
$$

where $X_{i}^{t}$ is the position of the current solution in $i$-th dimension at $t$-th iteration, $P_{i}{ }^{t}$ is position of the target point in $i$ th dimension at $t$-th iteration, and $r_{1}, r_{2}, r_{3}, r_{4}$ are random numbers with $r_{4} \in[0,1]$.

In the above pair of equations, $r_{1}$ defines the next location region. It could be located either inside or outside the space between target and solution. $r_{2}$ determines how far the movement is towards or away from the target point. $r_{3}$ defines a random weight for the target and stochastically increases $\left(r_{3}>\right.$ 1) or decreases $\left(r_{3}<1\right)$ the effect of the target point in determining distance. Lastly, $r_{4}$ provides an equal transition from the sine function to cosine function or vice versa in Eq. (12).

The SCA algorithm has superior exploration and exploitation ability. Moreover, it escapes from the local optimum, and it converges quickly to the global optimum. Also, it has not been affected by the structure of the problem. The range of sine and cosine functions in Eq. (12) are adaptively adjusted with the given formula Eq. (13) to balance the exploration and exploitation stages of the algorithm.

$$
r_{1}=b-k \frac{b}{K}
$$

where $k$ is the current iteration, $K$ is the maximum number of iterations, and $b$ is a constant.

\subsubsection{Convex Optimization Algorithm}

Convex optimization algorithm is the class of minimization problems is used this study to describe the thruster allocation problem and assured global optimum solutions. The method for solving a nonlinear constrained quadratic optimization problem that can be formulated as

$$
\begin{gathered}
\text { minimize: } f(y) \\
\text { subject to: } h(y)=0, \\
y \geq 0
\end{gathered}
$$

where the cost function and the constaints can be rewritten as

$$
\begin{gathered}
f(y)=\frac{1}{2} y^{T} y \\
h(y)=A_{u} y-u=0
\end{gathered}
$$

where

$$
u=\left[\begin{array}{c}
F \\
\bar{u}_{c}^{(b)}
\end{array}\right]
$$

is the desired thrust vector, $F$ is the force generated in the maneuver direction $\left(F_{x}\right.$ or $\left.F_{y}\right), y$ is the thrust force vector. $A_{u}$ is the $4 \times 6$ allocation matrix formed according to maneuver direction.

The optimization problem aims to minimize fuel consumption with limited thrusters' usage. For instance, if the satellite performs the East maneuver, $u_{t i, x}{ }^{(b)}$ component of the $u_{t i}{ }^{(b)}$ will be used. In this case, $A_{u}$ becomes

$$
A_{u, i}=F_{\max }\left[\begin{array}{c}
u_{t i, x}{ }^{(b)} \\
\bar{r}_{t i}^{(b)} \times \bar{u}_{t i}{ }^{(b)}
\end{array}\right]
$$

where $F_{\text {max }}$ is the maximum allowable thrust, $u_{t i, x}{ }^{(b)}$ is the $x$ component of the $i$-th thruster unit vector. $\bar{r}_{t i}^{(b)}$ is position of the $i$-th thruster, which is given in Hata! Başvuru kaynağ bulunamadı.. $\bar{r}_{t i}^{(b)} \times \bar{u}_{t i}{ }^{(b)}$ denotes the torques provided by the $i$-th thruster.

The optimization algorithm guarantees global optimum solutions which provide proper thrusters' usage. The forces and torques provided by thrusters can be computed as follows

$$
\begin{gathered}
\bar{F}_{t}^{(b)}=F_{\text {max }} \sum_{i=1}^{6} \bar{u}_{t i}{ }^{(b)} y \\
\overline{\mathcal{T}}_{t}^{(b)}=F_{\text {max }} \sum_{i=1}^{6} \bar{r}_{t i}^{(b)} \times \bar{u}_{t i}{ }^{(b)} y
\end{gathered}
$$

Using $\overline{\mathcal{T}}_{t}^{(b)}$ and $\bar{F}_{t}^{(b)}$ one can express Eq. (5) and Eq. (1), respectively.

\section{Results and Discussion}

The simulations are performed to verify the efficiency of the optimization algorithm in terms of the ability to keep satellite within a station-keeping window of \pm 0.01 degrees longitude and \pm 0.05 degrees latitude, while the maximum error in the Euler angles (roll, pitch, yaw) are \pm 0.05 degrees. The attitude of the satellite with respect to $\mathcal{F}_{i}$ at the beginning of the simulation is produced with 2-1-3 Euler series angles. Therefore, the quaternion is produced without any singularity. The mass of the satellite is chosen as $m=1875 \mathrm{~kg}$, center of mass $\mathrm{CoM}=$ $[0,0,2]^{T} m$, and the inertia of the satellite is chosen as

$$
\hat{J}_{S}^{(b)}=\left[\begin{array}{ccc}
10000 & 0 & 0 \\
0 & 5000 & 0 \\
0 & 0 & 9000
\end{array}\right]
$$

The initial satellite states are listed in Table 2. The satellite is propelled by six thrusters whose positions are given in Table 3 . For practical reasons, we restrict the magnitude of the thrusts to $F_{\max }=10 \mathrm{~N}$. In this simulation, the satellite performs the East maneuver and $F_{x}=15 \mathrm{~N}$. The attitude of the satellite is 
controlled by four reaction wheels. The speed range of the reaction wheels are assumed to be equal to $\pm 4500 \mathrm{rpm}$. Inertia of the reaction wheels about their spin axis is chosen as $J_{w / w i}=$ $0.1 \mathrm{kgm}^{2}$. The torque range of the reaction wheels is $\pm 0.22 \mathrm{Nm}$. In order to solve the differential equations related with satellite attitude and orbital dynamics, Runge-Kutta 4 method is used with a step size of $0.05 \mathrm{sec}$. The optimal attitude control gains are calculated using SCA as $K_{p}=$ $\operatorname{diag}[1890.7,4005,878.5]$ and $K_{d}=$ $\operatorname{diag}[1499.1,1483.9,903.7]$. Wheel speed control gains are chosen as $K_{p, w}=0.457, K_{i, w}=0.459$ and $K_{t, w}=10.47$.

The parameters used in station-keeping and momentum unloading simulations are obtained from the optimization procedure discussed in Section 2. Figure 5a shows that the reaction wheels accelerate to the desired speeds. The speed of the reaction wheels fixes to $-100 \mathrm{rad} / \mathrm{sec}=954.92 \mathrm{rpm}$ as can be seen from Table 2 and the initial speed of RW1 and RW4 is $-1200 \mathrm{rpm}$. Because of this, RW1 and RW4 reach the desired speed in a longer time than RW2 and RW3. Figure 5b shows torques of each reaction wheel. As can be seen from the figure, torques are approaching to zero, which means that the momentum of the reaction wheels is unloaded. Due to the friction torques of the wheel, torques are not definitively zero. Furthermore, Figure $5 \mathrm{c}$ illustrates the thrusters torque commands from the attitude controller in the $x, y$, and $z$ axes.

Table 3. Initial satellite states

\begin{tabular}{|c|c|c|}
\hline $\begin{array}{c}\text { Satellite } \\
\text { position in } \mathcal{F}_{\boldsymbol{i}} \\
(\mathrm{km})\end{array}$ & \multicolumn{2}{|c|}{$\begin{array}{c}-3396.7311 \\
42037.9430 \\
-32.3488\end{array}$} \\
\hline $\begin{array}{c}\text { Satellite } \\
\text { velocity in } \mathcal{F}_{i} \\
(\mathrm{~km} / \mathrm{s})\end{array}$ & \multicolumn{2}{|c|}{$\begin{array}{c}-3.0637 \\
-0.2487 \\
0.0024\end{array}$} \\
\hline $\begin{array}{l}\text { Target position } \\
\text { in } \mathcal{F}_{e} \\
(\mathrm{~km})\end{array}$ & \multicolumn{2}{|c|}{$\begin{array}{c}4700 \\
4200 \\
0 \\
\end{array}$} \\
\hline $\begin{array}{c}\text { Attitude } \\
\text { Roll-Pitch-Yaw } \\
\text { (deg) }\end{array}$ & \multicolumn{2}{|c|}{$\begin{array}{c}85.3589 \\
89.4571 \\
-90.5866 \\
\end{array}$} \\
\hline $\begin{array}{c}\text { Rates } \\
(\text { deg/sec })\end{array}$ & \multicolumn{2}{|c|}{$\begin{array}{c}0 \\
-0.0042 \\
0\end{array}$} \\
\hline \multirow{4}{*}{$\begin{array}{l}\text { RW Speeds } \\
(r p m)\end{array}$} & RW1 & -1200 \\
\hline & RW2 & -1000 \\
\hline & RW3 & -1000 \\
\hline & RW4 & -1200 \\
\hline
\end{tabular}

Table 4. Positions of the thrusters

\begin{tabular}{|c|c|}
\hline Thruster & Position in $\mathcal{F}_{e}(\mathrm{~m})$ \\
\hline 1 & $\bar{r}_{t 1}=[0,-1,0]$ \\
\hline 2 & $\bar{r}_{t 2}=[0,-1,4]$ \\
\hline 3 & $\bar{r}_{t 3}=[-1,-1,4]$ \\
\hline 4 & $\bar{r}_{t 4}=[-1,1,0]$ \\
\hline 5 & $\bar{r}_{t 5}=[1,-1,0]$ \\
\hline 6 & $\bar{r}_{t 6}=[1,1,4]$ \\
\hline
\end{tabular}
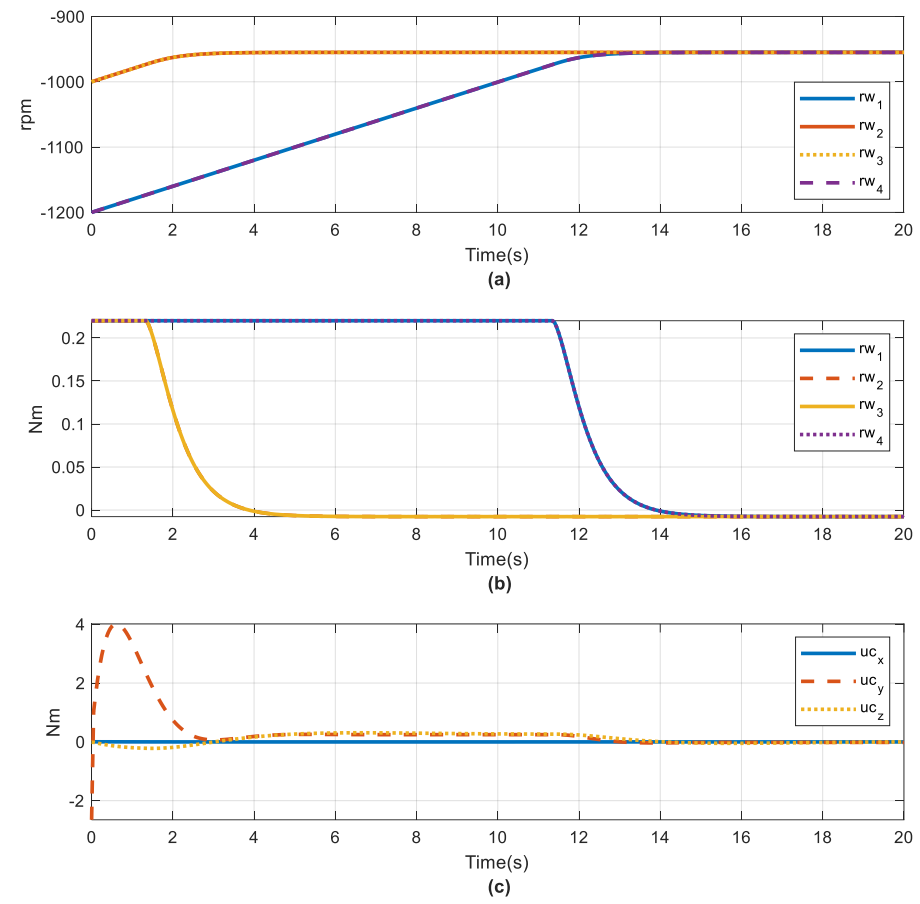

Figure 5. a) $R W$ speed, b) $R W$ torque command, c) Thruster torque command

Figure 6 shows the quaternion error as a function of time. As can be observed, quaternion error is within the acceptable limits for GEO satellite. Roll-pitch-yaw error angles are depicted in Figure 7a which shows that the constraints on the error angles are satisfied. Figure $7 \mathrm{~b}$ shows the satellite angular rates.
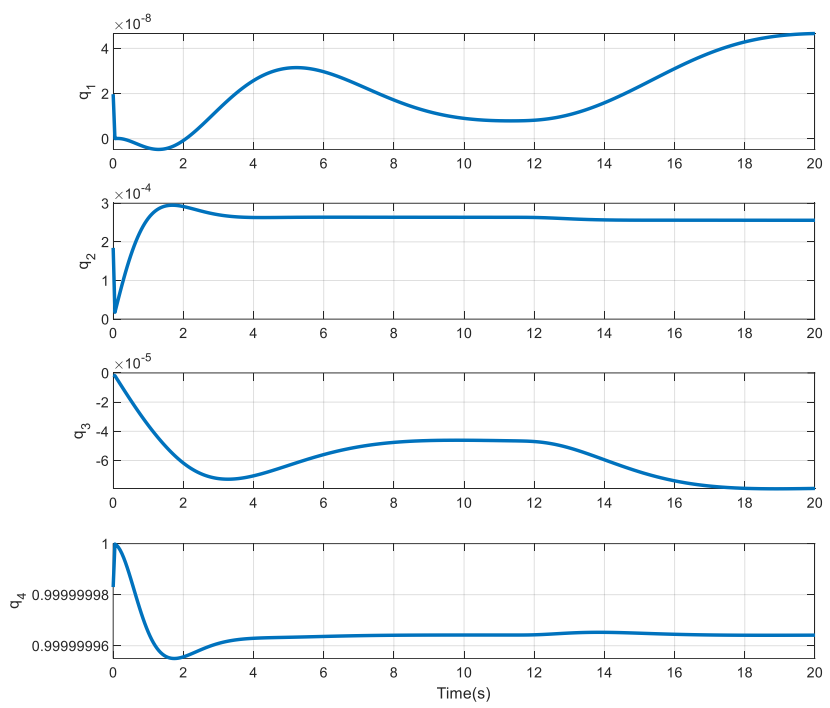

Figure 6. Quaternion error 


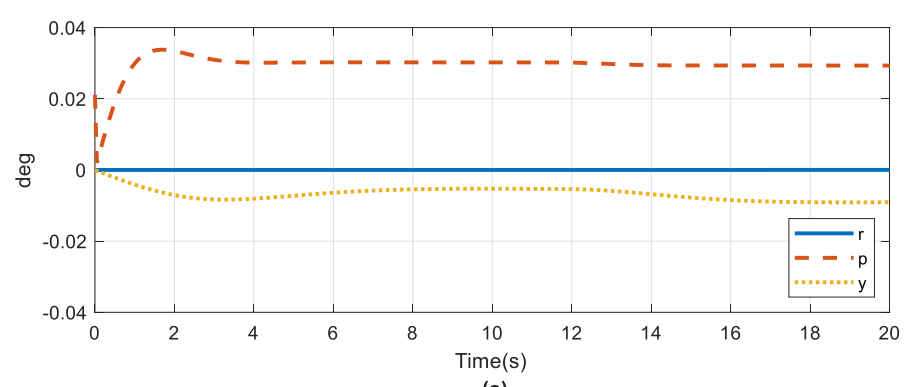

(a)

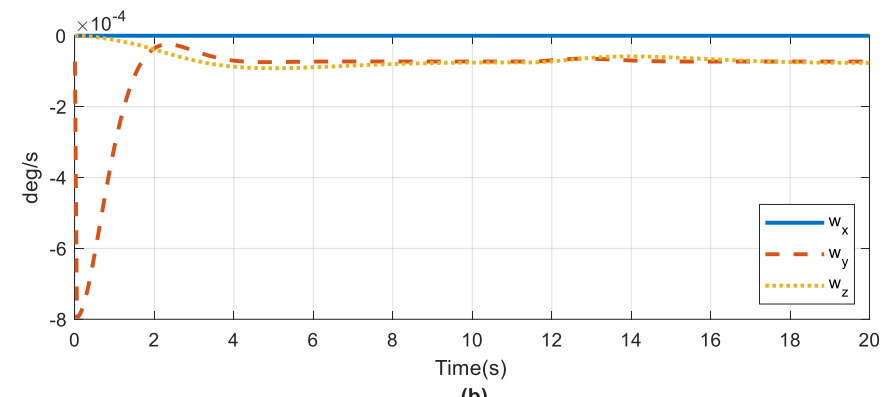

(b)

Figure 7. The errors in a) Euler angles, b) Angular velocity

\section{Conclusions}

In this paper, we proposed a control allocation method that suggests simultaneous orbit correction and momentum management. We obtained the optimal control parameters that reduce the use of chemical thrusters in GEO satellites. With the methods proposed in this paper, the satellite is maintained to point to an area on Earth while ensuring both orbital correction and momentum unloading. The reaction wheel speed controller has allowed the dumping of the momentum from the reaction wheels. Numerical simulations are presented to verify the effectiveness of the method.

\section{References}

Park, B., Tank, M., Bang, H., Park, C., \& Jin, J. (2005). A new approach to on-board stationkeeping of GEO-satellites. Aerospace Science and Technology, 722-731.

Chao, C. C., \& Baker, J. M. (1983). On the propagation and control of geosynchronous orbits. Journal of the Astronautical Sciences, 31, 99-115.

Curtis, H. (2010). Orbital Mechanics for Engineering Students. Daytona Beach Florida: Butterworth-Heinemann.

Emma, B. P., \& Pernicka, H. J. (2003). Algorithm for Autonomous Longitude and Eccentricity Control for Geostationary Spacecraft. Journal of guidance, control, and dynamics, 26(3), 483-490.

Bruijn, F., \& Theil, S. (2016). Geostationary Satellite StationKeeping Using Convex Optimization. Journal of Guidance, Control, and Dynamics, Vol.39, No.3.

Losa, D. (2007). High vs Low Thrust Station Keeping Maneuver Planning for Geostationary Satellites. Paris: École Nationale Supérieure des Mines de Paris.

Guelman, M. M. (2014). Geostationary satellites autonomous closed loop station keeping. Acta Astronautica, 9-15.

Markley, F. L., \& Crassidis, J. L. (2014). Attitude Kinematics And Dynamics. In Fundamentals of Spacecraft Attitude Determination and Control (pp. 67-84). New York: Springer.
Mirjalili, S. (2016). SCA: A sine cosine algorithm for solving optimization problems. Knowledge-BasedSystems, 96, 120133.

Özgören, M. K. (2007). Kinematic Analysis of Spatial Mechanical Systems Using Exponential Rotation Matrices. Journal of Mechanical Design, 129, 1144-1152.

Satpute, S., \& Emami, M. R. (2019). Concurrent Station Keeping and Momentum Management of Geostationary Satellites. The Journal of the Astronautical Sciences, 66, 341-360.

Shrivastava, S. K. (1978). Orbital Perturbations and Stationkeeping of Communication Satellites. American Institute of Aeronautics and Astronautics, 15(2), 67-78.

Thomas, D. (2016). A Comparison of GEO Satellites Using Chemical and Electric Propulsion. Retrieved from www.colorado.edu.

Weiss, A., Kalabic, U. V., \& Cairano, S. D. (2018). Station keeping and momentum management of low-thrust satellites using MPC. Aerospace Science and Technology, 76, 229241. 